\title{
Colloidal Gold as a Cy tochemical Marker in Electron Microscopy
}

\author{
Marc Horisberger \\ Research Department, Nestlé Products Technical Assistance Co., Ltd., La Tour-de-Peilz, Switzerland
}

\begin{abstract}
Colloidal gold is orange to red, displays electron-opaque properties and is capable of strong emission of secondary electrons. As gold particles can be produced in different sizes and can be labelled with macromolecules which keep their specific properties, gold markers have found uses in light and fluorescent microscopy, and many applications in scanning and transmission electron microscopy.
\end{abstract}

In biology, the most sophisticated analysis performed in vitro will never suppress the urge of an investigator to visualize the exact location of a cell component.

From the time the Dutch naturalist Antonie van Leeuwenhoek (1632-1723) made his first discoveries with a simple instrument, microscopy has indeed proved to be a powerful tool for understanding the microcosm. Thanks to patient efforts and to an amazing skill in using lenses, van Leeuwenhoek was able to obtain results which, at the time, were thought to be truly marvellous. His experiments became so popular that it was fashionable in the upper class society of Delft to find distraction, satisfaction and even joy in observing nature through his primitive microscopes. These inner feelings are still strongly felt by modern researchers using much more powerful instruments.

Clearly, van Leeuwenhoek was a self-taught microscopist, but his observations led to many discoveries of great importance. He was the first to observe protozoa, spermatozoids and red blood cells, and the first representation of a bacterium is to be found in one of his drawings of 1682 .

The development of optical microscopes has continued since that time, but the limits imposed by the wavelengths of visible light prompted the search for high resolution techniques. The first transmission electron microscopes having better resolution than light microscopes were built in 1932. Thirty years later, the scanning electron microscope was introduced. Scanning electron microscopy (SEM) gives a three-dimensional quality to specimen images. Normally, the instrument is operated by scanning, or sweeping, a very narrow beam of electrons back and forth across a metal-coated specimen, revealing its surface features rather than its internal structure.

The possibility of localizing specific tissue components attracted the early microscopists, but it was
Raspail (1794-1878), a French botanist, pharmacist, microscopist and politician, who first used the microscope to study the chemical reactions of tissue materials. He is considered to be the founder of histochemistry and some of the reactions which he discovered are still applied today. Over the years, a large number of techniques has been developed to identify, locate and quantify specific tissues and cell components. Among the methods having a narrow specificity, the use of fluorescent antibodies was introduced in 1941 by Coons et al. (1). A great advance was then achieved at the ultrastructural level with the development of enzyme cytochemistry $(2,3,4)$ and the application of particulate markers, such as ferritin, conjugated to antibodies $(5,6)$. Ferritin is a large molecule, of weight 800000 , with a protein shell of about $12 \mathrm{~nm}$ outer diameter surrounding a core of ferric hydroxide phosphate containing more than 2000 atoms of iron. In the transmission electron microscope, the core of ferritin can be seen as a dark spot. Although the ferritin technique is widely used and is a powerful tool in the hand of cytochemists, the method is rather time-consuming and expensive.

A new metallic and particulate marker was introduced more recently, namely colloidal gold. Its first application as a specific marker for transmission electron microscopy (TEM) was described in 1971 (7). The gold method was further developed by Horisberger et al. in 1975 for SEM (8) and in 1979 for fluorescent microscopy (9). Gold particle mapping by X-rays was reported in 1979 (10). The preparation of gold markers has been described in detail by Horisberger and Rosset (11) and by Geoghegan and Ackerman (12), and the method has been discussed in general articles $(13,14,15)$. The interested reader should refer to these articles.

Dispersions in which the particles are large compared with the magnitude of ordinary molecules, but 
still small enough to possess reasonable stability, are in general called colloidal dispersions, colloidal solutions or sols. The name colloidal was coined in 1861 by the Scottish chemist Thomas Graham (1805-1869) from the Greek word for glue. The Italian Enrico Selmi was the first to give a precise description of colloids in the years 1845 to 1860 and he built a theory of which some aspects are still valid today. However, Selmi's work attracted less attention than Graham's studies which were widely circulated, and to this day Graham has held the title of 'father of colloids'.

\section{Colloidal Gold}

Colloidal gold, prepared by reducing a dilute solution of gold chloride, is usually of a striking orange to red colour which it retains for many years. Although colloidal gold was known to the alchemists of the 17th century, it was Michael Faraday (1791-1867) who first made a scientific study of its preparation and properties. Some of Faraday's original gold dispersions in water, prepared in 1857, are still preserved at the Royal Institution in London. Faraday also discovered that addition of small amounts of electrolytes turns the colour of the sols from ruby to blue and coagulates them. More important, he demonstrated that these effects can be prevented by addition of gelatin and other macromolecules (16).

The facility with which its colour may be changed is one of the most curious properties of colloidal gold. No other hydrosol has been shown to change colour by coagulation, with the exception of that of silver under certain conditions. This phenomenon has not yet received an adequate explanation.

Many varieties of colloidal gold are known. They have been produced by reducing gold salts with at least 50 mineral and organic reagents such as phosphorus, formaldehyde, ethanol, tannic acid, ascorbic acid and sodium citrate. Depending upon the method used, the particles vary in size. For cytochemical uses, gold colloids are prepared essentially by three procedures. The smallest particles, $\mathrm{Au}_{5}$ - the subscript conveniently indicates the mean diameter of the particles in nanometres - are obtained by the procedure of Faraday (16), boiling a dilute solution of gold chloride in the presence of phosphorus (7). $\mathrm{Au}_{12}$ particles are produced at room temperature by reducing gold chloride with sodium ascorbate $(13,15)$. Larger granules $\left(\mathrm{Au}_{16}\right.$ to $\left.A \mathrm{u}_{75}\right)$ are produced by boiling gold chloride in the presence of decreasing amounts of sodium citrate (17). While the formation of gold particles by the ascorbate method is practically instantaneous at room temperature, with phosphorus and citrate the boiling solution turns faintly blue and then changes to red, orange or violet, depending upon the size of the particles. The development of the colour can be just as fascinating today as it must have been to the alchemists whose 'potable gold' was also colloidal in character.

\section{Preparation of Gold Markers}

Colloidal gold particles are surrounded by clouds of ions, the presence of which is thought to be responsible for their stability. The particles carry a net negative charge which causes mutual repulsion. The addition of electrolytes results in a compression of the ionic double layer and a reduction of the radius of repulsive forces. As a result, gold sols coagulate. The coagulation process can be prevented by simply mix. ing a protein with a gold sol, thereby adding a protective coat to the particles. While Faraday stabilized golds sols against coagulation by electrolytes with gelatin, Faulk and Taylor used antisera and thus obtained a specific immunocolloid $\left(\mathrm{Au}_{5}\right)$ capable of interacting specifically with cell surface antigens (7). Following this initial work, many different researchers have prepared gold markers by labelling gold particles with a wide variety of macromolecules such as toxins, hormones conjugated to protein, polysaccharides, glycoproteins, protein A, enzymes, antisera, immunoglobulins, lectins and fluorescent probes - reviews are presented in (13) and (15). Most macromolecules bound to gold particles show no apparent change in their specific bio-activity. All available evidence indicates that macromolecules remain firmly attached to gold particles, presumably through a non-covalent binding process $(13,14,15)$.

The stabilization of colloidal gold by protein depends upon a number of factors such as $\mathrm{pH}$, the electric charge of the molecule and its molecular weight (11 to 15). Once the optimal conditions for stabilizing a sol have been established by a simple coagulation test with sodium chloride $(7,11)$, gold markers may be readily prepared on a large scale. The colloid is added to a sufficient amount of macromolecules dissolved in water or possibly in a very dilute sodium chloride solution. The colloid is further stabilized against the possible formation of aggregates by adding polyethylene glycol - the most effective being Carbowax 20- $M$ of Union Carbide (8, 13) - and centrifuged. By this step, the colloid is concentrated and freed of unbound macromolecules. Finally, the colloid is suspended in a suitable buffer containing polyethylene glycol. The whole procedure can easily be completed in 3 to 4 hours. The stability of gold markers during storage at $4^{\circ} \mathrm{C}$ is generally excellent (15).

\section{Applications of Gold Markers}

$\mathrm{Au}_{5}$ to $\mathrm{Au}_{75}$ particles have been used to mark specimens either by the direct or the indirect methods. In the former, specimens are directly incubated with the gold marker in a single step. In the 

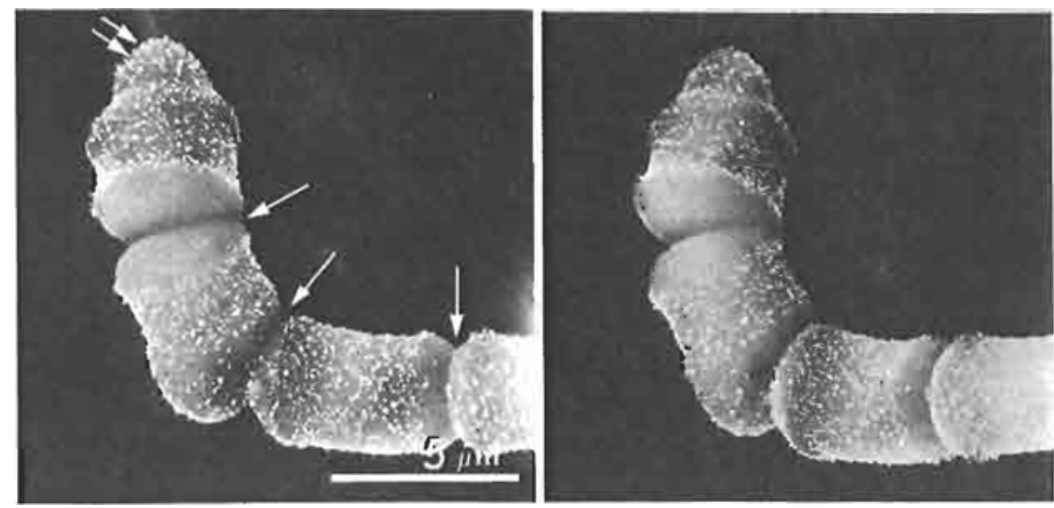

Fig. 1 Stereoscopic SEM micrographs of the yeast Schizosaccharomyces pombe. The cells were marked for galactomannan by the indircet method. They were incubated with the Ricinus communis lectin specific for galactose. The divalent lectin bound to cell wall galactomannan was in turn narked with $\mathrm{Au}_{50}$ particles labelled with a galactan (guaran) which reacted with the free lectin binding site. Crosswalls established by fission were practically not marked (single arrows). However, the growing ends reacted with the marker (double arrow). The specimen was not coated with metal. The stereopairs are best viewed with an optical viewer. Alternatively, witb a little determination one can sce the cell in three-dimensions with the naked eye by allowing the right eye to see only the right-band figure and the left only the left-hand figure, and by enconraging the inages to become fused in the brain (stereopsis). However, most people achicve stereopsis more easily with inversion by crossing the eyes. The viewer holds a pencil between the figures. While looking with both eyes at the tip of the pencil, he raises it towards his eyes until the two images fuse. After (20)

latter, specimens are first incubated with a surface specific ligand, most often a lectin or an antibody, and then in one or more subsequent steps, the gold marker is attached to the bound ligand through specific interactions. Marking is achieved by agitating gently unfixed or glutaraldehyde-fixed specimens with an excess of gold marker. When marking is dense enough, it can be seen by means of light microscopy as an orange-red surface coating (12). The method has also found application in fluorescent microscopy when gold particles are labelled with a fluorescein (17) or a rhodamine (9) conjugate.

In SEM, the gold method has been used to mark a variety of cells such as yeast, red blood cells, platelets, hepatocytes and milk-fat globules $(13,15)$. One advantage of SEM is that comparatively large areas can be seen in detail. Contrary to other conventional SEM markers, gold markers are good emitters of secondary electrons. This property enables the observer to locate gold particles on a cell surface which is not coated with a metal. At present, with the type of instruments used, the most convenient size of gold marker is approximately $50 \mathrm{~nm}$, although particles as small as $\mathrm{Au}_{22}$ have found uses (15). Stereomicrographs facilitate differentiation between individual particles (Figure 1). Despite the simplicity of the method, SEM observations should be corroborated by TEM observations with smaller markers since some cell surface binding sites may not be ac- cessible to large size markers due to steric hindrance.

In TEM, gold markers are readily identified by their opacity to electrons and their characteristic shapes. The choice of the particle size depends upon the magnification used and consideration of the steric inaccessibility of binding sites. $\mathrm{Au}_{5}$ and $\mathrm{Au}_{20}$ particles have most commonly been used to mark virus, bacteria, yeast, plant cells and a great variety of animal cells $(13,15)$.

The method has found two applications of special interest in TEM, for which gold is unsurpassed by other particulate markers at present.

First, as the size of particles in monodisperse sols can be varied at will between 5 and $150 \mathrm{~nm}$ in mean diameter, gold markers are convenient for multiple marking $(10,18)$. This technique permits the precise evaluation of changes occurring on cell surfaces and the study of the spatial location of receptors relative to each other. In multiple marking experiments with gold particles, stereomicrographs must be taken to avoid false interpretation since apparently closely associated particles may be in different planes of the specimen (Figure 2).

Secondly, the possibility of marking intracellular components is another important application of colloidal gold preparations, since many difficulties in achieving this goal are encountered using other particulate markers. In contrast to ferritin conjugates, gold markers are easily recognized on thin sections to 

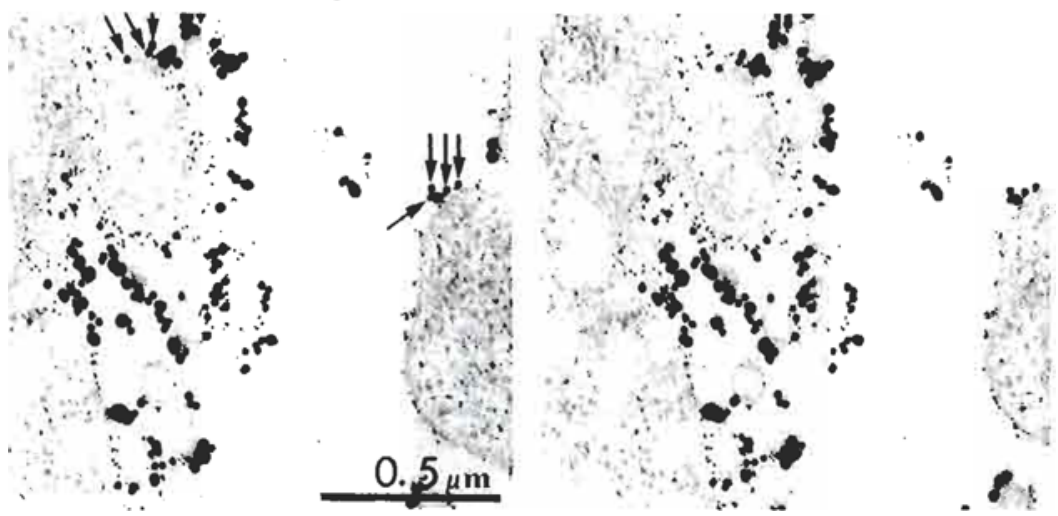

Fig. 2 Stereoscopic TEM micrographs of triple-marked mouse embryo fibroblasts. Binding sites (glycoproteins) for concanavalin A (Con A), soya bean (SBA) and wheat germ agglutinin (WGA) were located by marking glutaraldehyde-fixed cells successively with Con $A-A u_{5}, S B A-A u_{17}$ and WGA$A u_{26}$. Some SBA-Au $u_{17}$ particles are slown by the arrows. When the stereopair is examined, most of the markers are bound by spatially separated sites. Unpublished documents by Horisberger and Vonlanthen

which they bind nonspecifically to only a small extent. Marking is achieved by floating ultrathin sections on a droplet of gold marker. Again, both the direct and the indirect methods have been used (Figure 3). At present the most general method is the indirect protein A-gold method (19) which is based on the ability of this protein to interact specifically with a wide variety of immunoglobulins from several species.

As gold particles strongly absorb visible light at a single peak of absorption ( $\hat{\lambda}_{\max } 520$ to $550 \mathrm{~nm}$ ), a sim- ple spectrophotometric method has been developed to determine the number of particles bound per cell (11, 13, 15). The latter depends upon a number of factors such as the ionic strength of the buffer, the size of the gold particles and the method utilized to mark the specimen (direct or indirect). As a rule, when the size of the marker increases, the number of bound particles decreases, sometimes abruptly $(13,15)$. This indicates that binding sites close to the lipid bilayer are less accessible to large probes than receptors extending from the cell surface, or even that they are
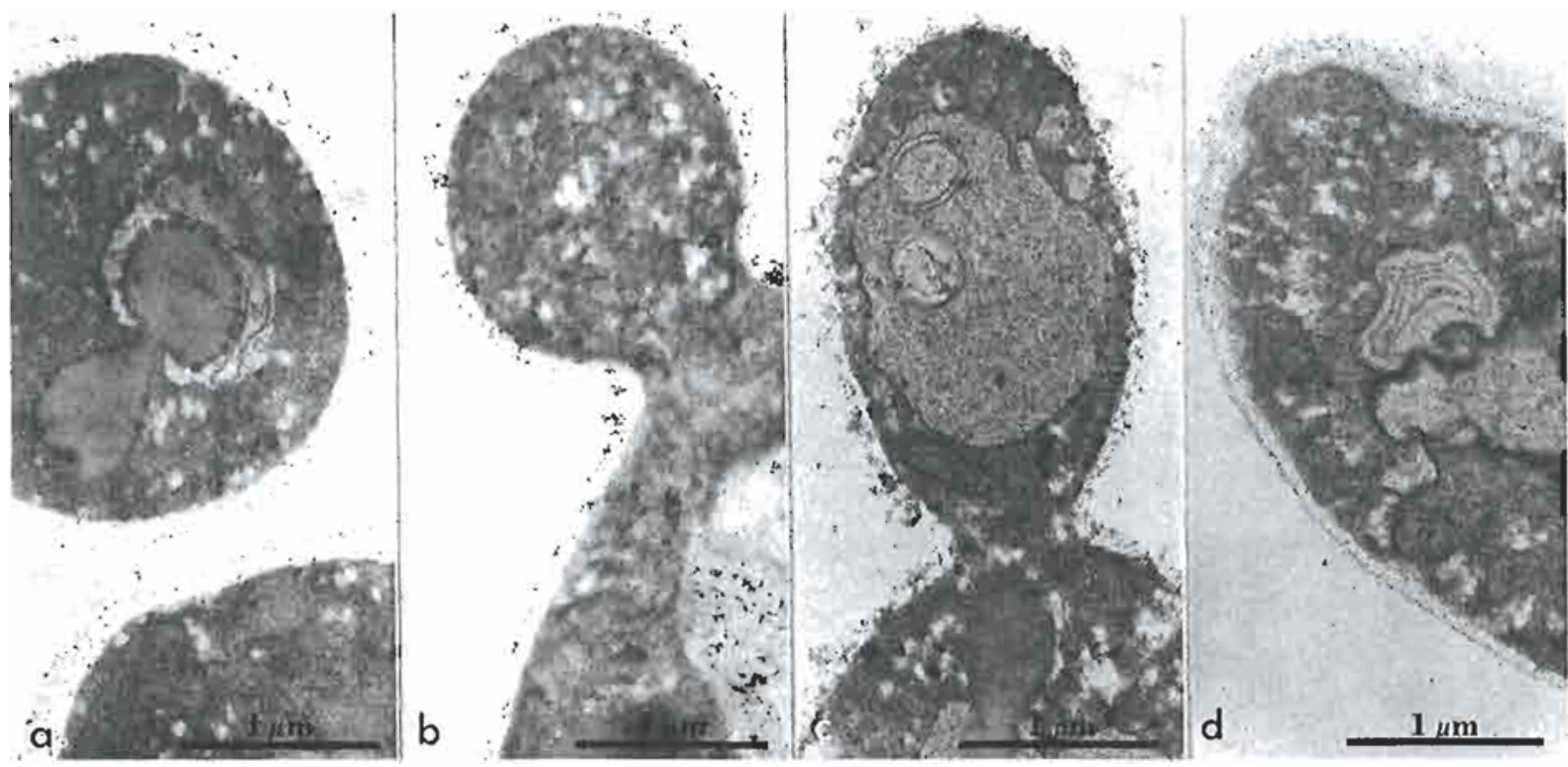

Fig. 3 In an example of the direct metlod of using gold markers, thin sections of Candida utilis were marked for mannan with Con $A \cdot A u_{5}$ (a) and anti-mannan antibodies- $A_{5}$ (b). The indirect nethod is illustrated by sections which were in-

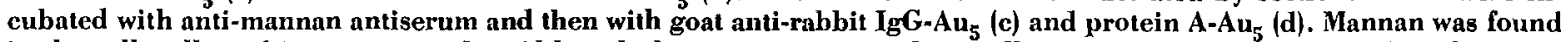
in the eell walls and in some vacuoles. Although the results were similar in all cases, the highest density of marking was achieved by the protein A-gold method. Unpublished observations by Horisberger and Vonlanthen 
inaccessible to them. Therefore, the use of probes of increasing size appears to be a tool for studying not only the lateral, but also the longitudinal distribution of cell surface binding sites. However, since the number of labelled particles bound to a surface is less than that of the free molecules, the gold method does not allow an absolute quantification of specific surface receptors. This restriction also applies to other particulate markers.

\section{Conclusion}

While the gold method has found some uses in histochemistry, its main application is in cytochemistry using both SEM and TEM. The method is general and its versatility resides in the wide variety of macromolecules which can be adsorbed onto gold particles. Gold markers can be prepared rapidly and inexpensively, they show little nonspecific adsorption and can be quantified by various methods. They are also useful for multiple marking experiments. Finally, using the technique, intracellular antigens can be located on thin sections on which the gold particles can be clearly identified.

\section{Acknowledgements}

The author thanks Mrs. J. Rosset for the scanning electron micrographs, Ms. $M$. Vonlanthen for the transmission electron micrographs, Mrs. Beaud for the photographic work and Professor B. Hirt (Swiss Institute for Experimental Cancer Research, Lausanne) for the gift of mouse embryo fibroblasts.

\section{References}

1 A. H. Coons, H. J. Creech, R. N. Jones and E. Berliner, 7 . Immunol., 1942, 45, 159-170

2 I', K. Nakane and G. B. Pierce, 7. Histochem. Cytochem., $1966,14,929-93$

3 S. Avrameas, Bull. Soc. Chim. Biol, 1968, 50, 1169.1178

4 L. A. Sternberger, P. H. Hardy, I. I. Cuculis and H. G. Meyer, F. Histochem. Cytochem., 1970, 18, 315-333

5 S. J. Singer, Nature, 1959, 183, 1523.1524

6 S. J. Singer and A. F. Schick, 7. Biophys. Biochem. Cytol., $1961,9,519.525$

7 W. P. Faulk and G. M. Taylor, Immunochemistry, 1971, 8, 1081-1083

8 M. Horisberger, J. Rosset and H. Bauer, Experientia, 1975, 31, 1147-1148

9 M. Horisberger and M. Vonlanthen, Histochemistry, 1979 64, $115-118$

10 L. C. Hoyer, J. C. Lee and C. Bucana, in 'SEM/1979/III', SEM Inc., AMF O'Hare, IL. 60666, pp. 629-636
$11 M$. Horisberger and J. Rosset, 9 . Histochem. Cytochem., $1977,25,295-305$

12 W. D. Geoghegan and G. A. Ackerman, \%. Histochem Cytochem., 1977, 25, 1187.1200

13 M. Horisberger, Biol. Cell, 1979, 36, 253-258

14 S. L. Goodman, G. M. Hodges and D. C. Livingston, in 'SEM/1980/I', SEM Inc., AMF O'Hare, IL, 60666, pp. $136-146$

$15 M$. Horisberger, in 'SEM/1981', SEM Inc., AMF O'Hare, IL, 60666, in press

16 M. Faraday, Ann. Phys., 1857, 101, 383

17 G. Frens, Nature Phys, Sci., 1973, 241, 20-22

$18 M$. Horisberger and $M$. Vonlanthen, 7 . Microsc., 1979, 115 97.102

19 J. Roth, M. Bendayan and L. Orci, J. Histochem. Cytochem., $1978,26,1074 \cdot 1081$

20 M. Horisberger, M. Vonlanthen and J. Rosset, Arch. Microbiol., 1978, 119, 107-111

\section{The Development of Gold Drugs}

Three reviews have appeared in recent years, which indicate that the development of gold drugs for use in medicine may be entering a new and less empirical phase. They are the following: 'The Biological Chemistry of Gold: a Metallodrug and Heavy-Atom Label with Variable Valency' by P. J. Sadler of Birbeck College, University of London, (Struct. Bonding, 1976, 29, 171-214); 'The Mammalian Biochemistry of Gold: an Inorganic Perspective of Chrysotherapy', by C. F. Shaw III of the University of Wisconsin-Milwaukee, (Inorg. Perspect. Biol. Med., 1979, 2, 287-355) and 'The Chemistry of the Gold Drugs Used in the Treatment of Rheumatoid Arthritis', by D. H. Brown and W. E. Smith of the University of Strathclyde, (Chem. Soc, Rev., 1980, 9, (2), 217-240).

Although gold is absorbed by some plants, it cannot normally be detected in animal tissues and is not regarded as an essential element in living systems. Its administration is therefore akin to that of toxic elements such as mercury and basically different from that of biologically used elements such as copper and iron.

Gold distributes widely in the body in which it undergoes a variety of reactions. The most important of these appear to be with thiols, and it undoubtedly exercises some of its biological effects through such reactions and the disturbance which they cause to normal metabolism. New knowledge and new techniques are making studies of these reactions more effective. As is emphasized by Brown and Smith, however, gold is not applied in the form of one drug only and the in vivo reactions of compounds such as triethylphosphinegold chloride, Auranofin and sodium aurothiomalate are likely to be quite different. They do not appear to produce a common metabolite on administration and their clearance rates from particular tissues vary, as well as their effects on enzymes. This makes the study of the fundamentals of gold therapy particularly difficult.

Nevertheless, the fact that gold complexes are effective against such a widespread disease as rheumatoid arthritis, for which there is no acknowledged cure, makes their further study important. Although applications of these complexes have been increasing in recent years, their use is still restricted by the toxic effects which are often associated with their administration. There is no reason to believe, however, that their toxic and therapeutic effects are necessarily linked and that research will not lead to more effective complexes and/or to improved conditions of administration. 